\title{
Stabilization of Nanocrystalline Copper by Tantalum Grain Boundary Segregation
}

\author{
Sufeng Wei ${ }^{1}$, Xinming $\mathrm{Hu}^{2}$, Xianglei Liu ${ }^{3 *}$, Guoyong Wang ${ }^{*}$ \\ ${ }^{1}$ Key Laboratory of Advanced Structural Materials, Changchun University of Technology, Changchun, China \\ ${ }^{2}$ Ansteel Group Iron and Steel Research Institute, Anshan, China \\ ${ }^{3}$ National Key Laboratory of Science and Technology on Helicopter Transmission, Nanjing University of Aeronautics and \\ Astronautics, Nanjing, China \\ ${ }^{4}$ Key Laboratory of Automobile Materials, Department of Materials Science and Engineering, Jilin University, \\ Changchun, China \\ Email: *xliu@nuaa.edu.cn, *materwang@jlu.edu.cn
}

How to cite this paper: Wei, S.F., Hu, X.M., Liu, X.L. and Wang, G.Y. (2021) Stabilization of Nanocrystalline Copper by Tantalum Grain Boundary Segregation. Open Journal of Physical Chemistry, 11, 157-167.

https://doi.org/10.4236/ojpc.2021.113009

Received: June 11, 2021

Accepted: July 31, 2021

Published: August 3, 2021

Copyright (c) 2021 by author(s) and Scientific Research Publishing Inc. This work is licensed under the Creative Commons Attribution International License (CC BY 4.0).

http://creativecommons.org/licenses/by/4.0/

\begin{abstract}
Nanocrystalline $\mathrm{Cu}$-Ta alloy films were deposited on glass slides by magnetron sputtering. Microstructure characterization proved that most of the tantalum atoms are segregated in the grain boundaries. Nanoindentation creep measurements were performed on it to uncover the stability mechanism of grain boundary segregation on nanocrystalline materials. It is found that segregation can effectively slow down the creep strain rate and the grain boundary activities. The suppressed grain boundary activities endow the alloy with a stable microstructure during plastic deformation and annealing.
\end{abstract}

\section{Keywords}

Nanocrystalline, Segregation, Creep, Nanoindentation, Grain Growth, Annealing

\section{Introduction}

Since the pioneering work of Gleiter [1], nanocrystalline (NC) materials have received enormous attention in the past decades [2]-[8]. It is well known that this class of materials displays not only outstanding mechanical properties, such as high tensile strength and high strain rate sensitivity [9] [10] [11], but also enhanced physical properties, e.g. magnetic properties [12]. It is wildly accepted that these superior characteristics stem from the ultrafine grain size or the high fraction of atoms on grain boundaries, the so-called size effect [13]. But such a high fraction of grain boundaries also comes with an inherent instability. Many 
NC materials of interest for both fundamental study and engineering application are now recognized as substantially out of equilibrium and undergo rapid evolution to coarser structures even at modest temperatures [14] [15] [16]. Such coarsening tendencies impede the use of these materials at ambient temperature, especially the use as structure materials which always serve a very long period.

The coarsening tendencies of NC materials are related to the intensive activities of GB, such as GB sliding and GB migration [14]-[20]. Although these GB activities are necessary for improving the plastic deformation [21] [22] [23] [24] [25], we have to cease it for stabilizing the structure and maintaining the superior characteristics of NC materials. Alloying with immiscible elements is a promising approach [26]. Immiscible elements tend to strongly segregate to GBs [27], in analogy to microemulsions where the addition of surfactant is used to stabilize interfacial area, reducing the free energy and slowing down the grain growth. In addition, immiscible elements can effectively pin GBs [28] [29]. Cu-Ta is such a suitable immiscible system [30]. The individual element of this system has different crystalline structures and negligible mutual solubility in the solid state. The diameter of $\mathrm{Ta}$ atom is much bigger than $\mathrm{Cu}$ atom, which makes them tend to segregate in the GBs of $\mathrm{Cu}$. In this paper, we used magnetron sputtering to synthesize a $\mathrm{Cu}-\mathrm{Ta}$ (Ta 5\%) film on glass substrate. The stabilization of this immiscible alloy system is compared with a pure copper film synthesized at the same condition. The alloy exhibits superior stability at modest temperature. And the corresponding mechanism and GB activities are investigated by nanoindentation creep experiment.

\section{Experimental}

The used samples of pure copper (named $\mathrm{NC} \mathrm{Cu}-1$ ) and $\mathrm{Cu}-\mathrm{Ta}$ (CT-1) films with a thickness of $\sim 5 \mu \mathrm{m}$ are deposited on glass slides by a FJL-560 magnetron sputtering equipment. Two targets, one contains $99.99 \%$ copper and the other one contains $\mathrm{Cu} 95 \%$ and $\mathrm{Ta} 5 \%$, were used in this experiment. The samples were sputtered under $1 \mathrm{~Pa}$ argon atmosphere at the power of $50 \mathrm{~W}$ for $30 \mathrm{mi}$ nutes. Then the as-deposited samples were annealed in the GSL-1600x tube furnace at $150^{\circ} \mathrm{C}$ for 2 hours (named NC Cu-2 and CT-2) and at $200^{\circ} \mathrm{C}$ for 3.5 hours (named NC Cu-3 and CT-3). Transmission electron microscopy (TEM) observations were performed on a JEM 2010 high-resolution electron microscopy with an acceleration voltage of $200 \mathrm{kV}$. The crystallographic structure was analyzed using an x-ray diffractometer (XRD) (D/max 2500 PC). Nanoindentation tests were performed at room temperature on an Agilent Nanoindenter G200 with a Berkovich diamond indenter where the nominal tip radius of curvature of $\mathrm{R}$ is about $50 \mathrm{~nm}$. Consequently, the minimum depth for self-similar indentation, determined from the equation $\mathrm{R}\left(1-\sin 70.3^{\circ}\right)=0.06 \mathrm{R}$ is about $3 \mathrm{~nm}$ [31]. The displacement and load resolutions of the instrument are $0.01 \mathrm{~nm}$ and $50 \mathrm{nN}$. To avoid the substrate effect, the contact depth was controlled to below $1 / 10$ of the film thickness. An initial load ramp at rate $0.1 \mathrm{~s}^{-1}$ was used, followed by hold- 
ing the load at the peak load of $8 \mathrm{mN}$ for $60 \mathrm{~s}$ to allow creep to occur. Then the load was reduced to $10 \%$ of the peak load and was held constant to record the thermal drift rate during the experiment. All results shown later were corrected for thermal drift with the rate measured during this period. Moreover, the hardness measurements were performed without load holding. Indentation at each load was repeated at least ten times.

\section{Results and Discussion}

Figure 1 shows the typical XRD patterns of the $\mathrm{Cu}$ and $\mathrm{Cu}$-Ta samples. Five strong diffraction peaks at 2-theta values of $43.297^{\circ}, 50.433^{\circ}, 74.130^{\circ}, 89.931^{\circ}$ and $95.139^{\circ}$ can be indexed to diffractions of the (111), (200), (220), (311) and (222) crystallographic planes of fcc copper (JCPDS No.04-0836). None peaks belonging to tantalum phase were found even in the $\mathrm{Cu}$-Ta pattern. So the widely observed tantalum atomic nanoclusters or precipitates in the $\mathrm{Cu}-\mathrm{Ta}$ alloy with high concentration of tantalumare absent in this $\mathrm{Cu}$-Ta pattern [30]. The grain size of $\mathrm{NC} \mathrm{Cu}$ and $\mathrm{Cu}-\mathrm{Ta}$ alloy were both calculated by the full width at half maximum (FWHM) of (111) diffraction peak using Scherrer's formula. The calculated grain size of $\mathrm{NC} \mathrm{Cu}$ is $15 \mathrm{~nm}$, which is comparable with that of $\mathrm{Cu}-\mathrm{Ta}$ alloy $(15 \mathrm{~nm})$. So the doping of tantalum atoms has neither effect on the matrix crystallography nor on the grain size. The microstructure of the $\mathrm{Cu}$ and $\mathrm{Cu}-\mathrm{Ta}$ alloy were characterized using TEM observation, and the corresponding images were shown in Figure 2(a) and Figure 2(b). Both samples have a similar microstructure. The grains are uniform and equiaxial. Some nanoscale twins are observed in a little bit bigger grains. The mean intercept method was also performed to calculate the grain size on the TEM images. The mean grain size of $\mathrm{NC} \mathrm{Cu}$ is $17 \mathrm{~nm}$ based on measurement on about 500 grains, consistent with the $\mathrm{XRD}$ calculated value. The mean grain size of $\mathrm{Cu}-\mathrm{Ta}$ alloy is $16 \mathrm{~nm}$. The doping of tantalum atoms has little effect on the microstructure. As annealing, the grain of $\mathrm{NC} \mathrm{Cu}$ dramatically increased. The microstructure of $\mathrm{NC} \mathrm{Cu}$ after annealing

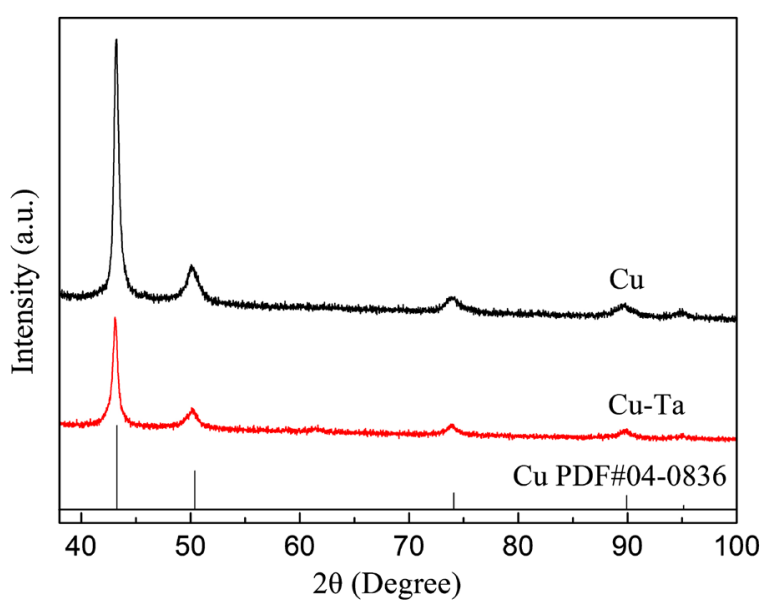

Figure 1. X-ray diffraction patterns of the as-deposited NC copper and $\mathrm{Cu}-\mathrm{Ta}$ alloy samples. 

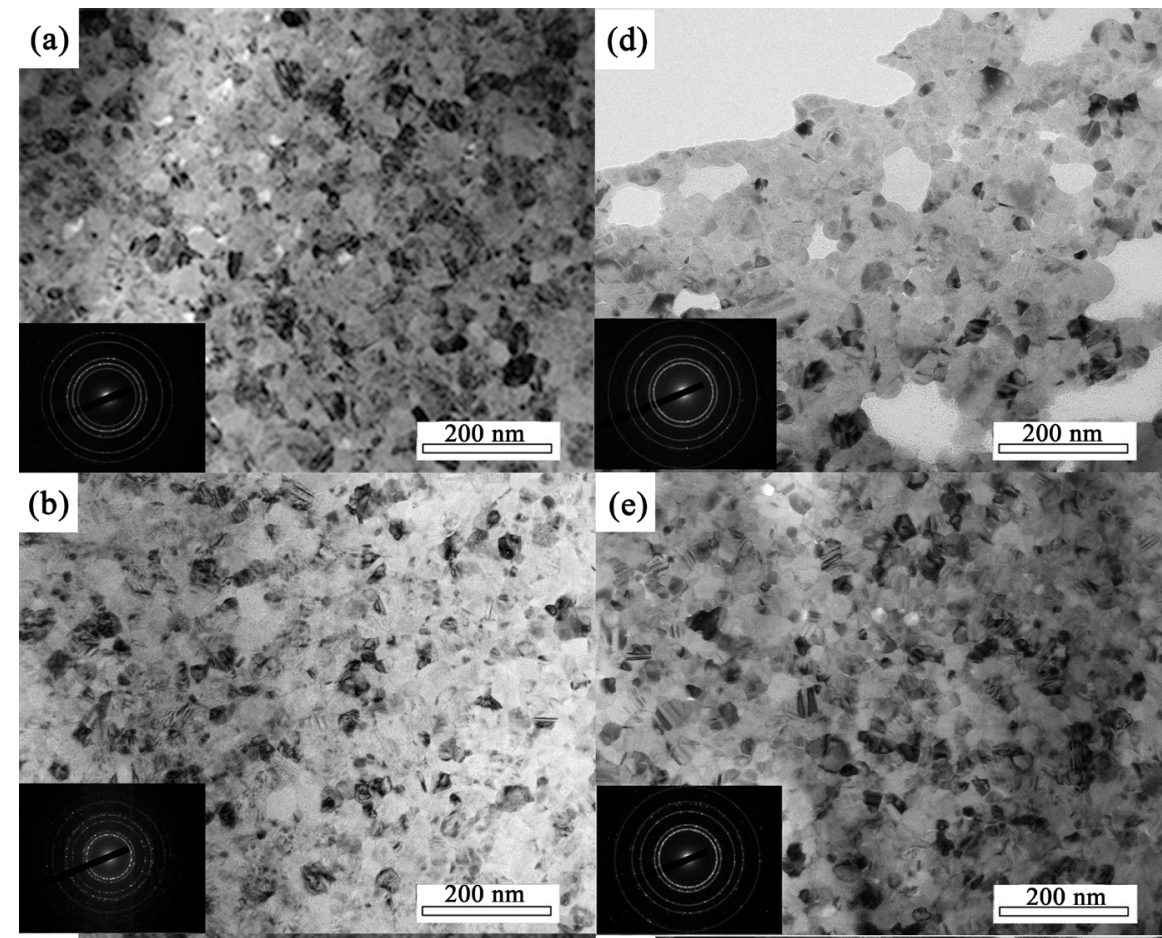

(e)
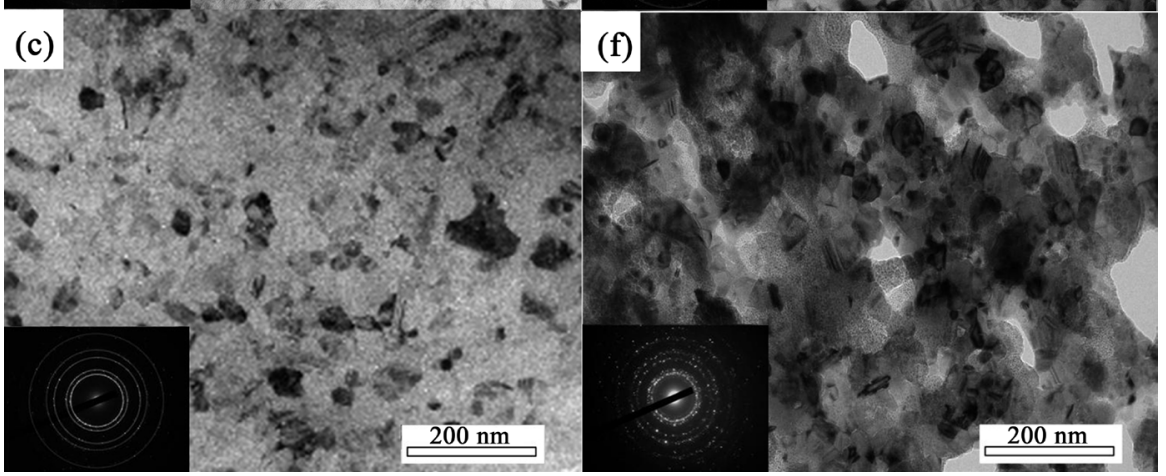

Figure 2. TEM images of (a) NC Cu-1, (c) 2, (e) 3 and (b) CT-1, (d) 2, (f) 3. The inset in each image is the corresponding selected-area diffraction patterns.

was also observed by TEM and the corresponding images were shown in Figure $2(\mathrm{c})$ and Figure 2(e). After two hours annealing at $150^{\circ} \mathrm{C}$, the mean grain size of $\mathrm{NC} \mathrm{Cu}$ increased to $25 \mathrm{~nm}$ based on the mean intercept method on the TEM images. After 3.5 hours annealing at $200^{\circ} \mathrm{C}$, the grain size further increased to 36.34 $\mathrm{nm}$. But the $\mathrm{Cu}-\mathrm{Ta}$ alloy is relatively insensitive to the annealing. No matter annealing at $150^{\circ} \mathrm{C}$ for 2 hours or at $200^{\circ} \mathrm{C}$ for 3.5 hours, the microstructure of $\mathrm{Cu}-\mathrm{Ta}$ alloy remains constant. The statistical mean grain size based on TEM image is $17 \mathrm{~nm}$ for the sample annealing at $150^{\circ} \mathrm{C}$ for 2 hours. And the other one is $18 \mathrm{~nm}$. The hardness of each sample was investigated by nanoindentation. The hardness of $\mathrm{Cu}-1,2,3$ is 4.092, 3.815 and $2.738 \mathrm{GPa}$, respectively. And the hardness of CT-1, 2, 3 is 4.806, 4.362 and $4.361 \mathrm{GPa}$, respectively. Apparently, the doping of tantalum atoms intensively enhances the hardness. Although the CT-1 has the same grain size with $\mathrm{Cu}-1$, its hardness is much higher. The annealing at low temperature causes dramatic decline of hardness of NC copper. Such decline 
can't simply rationalized by grain growth following Hall-Patch relationship. For $\mathrm{Cu}$-Ta alloy film, only the initial annealing causes the decline of hardness and further annealing doesn't causes any change of hardness, although the grain size remains the same during annealing. So the dramatic hardness decline for NC copper and $\mathrm{NC} \mathrm{Cu}-\mathrm{Ta}$ alloy during annealing should mainly relate to grain boundary relaxation. Grain boundary relaxation causing hardness and strength decline has widely been found in experiment and computer simulation [32] [33].

In order to make clear the content and the distribution of tantalum in the alloy, the Energy Disperse Spectrum (EDS) in TEM was carried out on the Cu-Ta sample. The corresponding TEM image and the energy line scanning results are shown in Figure 3. According to EDS results shown in Figure 3(c), the tantalum content in the alloy is about $5 \%$. So the Ta content in the sputtered sample is the same as the target material. Carefully observing the energy line scanning result in Figure 3(b), it is interesting to find that the distribution of $\mathrm{Cu}$ and $\mathrm{Ta}$ is not uniform. The content of copper and tantalum atom intensively wave along the scanning line. Meanwhile the peaks of tantalum always overlapped with the valleys of copper. That means the place where there are a lot of tantalum atoms accommodate less copper atoms. We carefully measured the mean distance between adjoining peaks of tantalum or valleys of copper. The value is $14 \mathrm{~nm}$ which is close to the mean grain size of the alloy. So it can be concluded that most of tantalum are segregated in the GBs.

During self-similar indentation creep, the creep strain rate $\dot{\varepsilon}$ field and the stress $\sigma$ field scale, respectively, with an indentation strain rate and an indentation stress which are given by [34] [35].

$$
\dot{\varepsilon}=\frac{1}{h} \frac{\mathrm{d} h}{\mathrm{~d} t}, \sigma=\frac{p}{A_{c}},
$$

where $P$ is the indentation load, $h$ is the instantaneous indenter displacement, $t$
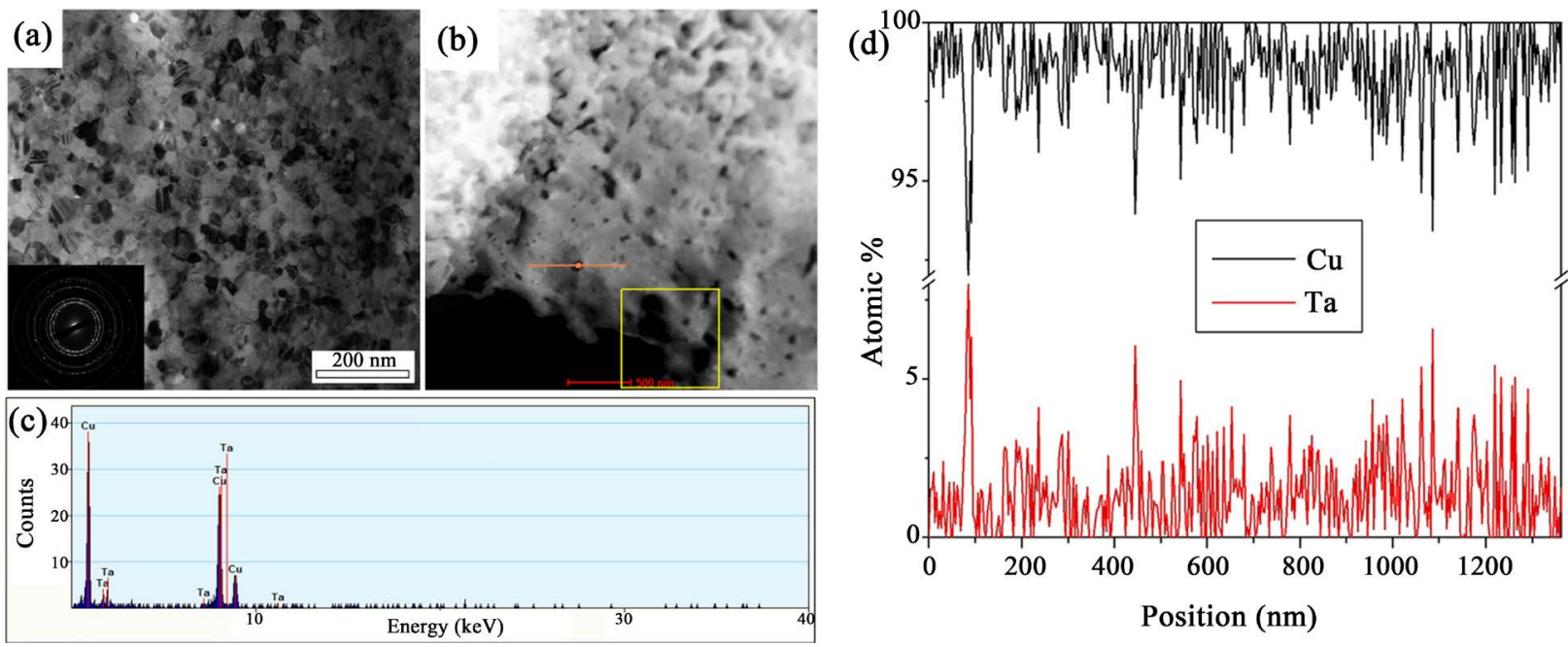

Figure 3. (a) A TEM image of the as-deposited Cu-Ta alloy; (b) the image show EDS analysis domain and line; (c) the EDS element content of the sample; (d) the corresponding elements distribution from EDS line scanning mapping. The inset is the corresponding selected-area diffraction patterns. 
is the time, and $A_{c}$ is the contact area. To calculate the displacement rate $\dot{h}=\mathrm{d} h / \mathrm{d} t$, the indenter displacement versus time curve at constant indentation load is fitted by an empirical law [35].

$$
h(t)=h_{0}+a\left(t-t_{0}\right)^{b}+c t,
$$

where $h_{0}, a, t_{0}, b$, and $c$ are fitting constants. Equation (2) is found to accurately fit the experimental creep curves at peak loads. Both the experimental and fitting results of $\mathrm{Cu}-1$ are shown in Figure 4(a). The corresponding strain rate is calculated by Equation (1) and plotted in Figure 4(b). For each sample there is an initial abrupt increase in creep depth, followed by a stage with a smaller rate of increasing creep depth. As the strain rates are calculated from these experimental data, the creep rate curves can also be divided into two stages as shown in Figure 4(b). In stage I, the creep rates decrease dramatically. In stage II, the creep rates tend to a constant value. The initial stage is known as transient creep. And the later corresponds to steady-state creep stage. Obviously, the steady-state creep strain rate of $\mathrm{NC} \mathrm{Cu}$ shows a dramatic decrease as the grain size increase. The strain rate in the end of the time duration is $0.010,0.009$ and 0.007 , respectively. $\mathrm{Cu}$-Ta alloy has a lower steady-state creep strain rate than $\mathrm{Cu}-3$ which has an even bigger grain size, twice the size of CT-1. The annealing on $\mathrm{Cu}$-Ta alloy neither enlarges the grain size nor affects the steady-state creep strain rate. As shown in the inset of Figure 4(b), the steady-state creep strain rate curve of CT-1 almost overlapped with that of CT-3. The final strain rate for CT-1 and CT-3 are 0.006 . Thermally activated mechanisms contributing to plastic deformation process in metals are often quantitatively interpreted by examining $m=\partial \ln s / \partial \ln \dot{\varepsilon} \quad$ [9]. The magnitudes of $m$ of NC Cu- 1 and CT- 1 were obtained by the indentation creep test for each holding loads, as shown in Figure 4(c). The magnitudes of $\mathrm{m}$ of NC Cu- 1 and CT- 1 are 0.49 and 0.52 , respectively.

It is well know that time-dependent (creep) flow is related to diffusion. For coarse crystalline metals, the diffusion paths are intragranular by the help of dislocation clime/glide or through dislocation tube or mass/vacancy flux. Meanwhile the diffusion paths in NC metals are mainly intergranular, through GB or by the help of GB sliding. The different creep mechanism can be reflected by the magnitude of the strain rate sensitivity value $\mathrm{m}$. The high strain rate sensitivity $m$ of each sample implies that GB diffusion and sliding are the dominant creep mechanism for all the samples. For the NC copper, the quasi-steady-state creep strain rate reduces along with the grain size growth, just the same as the description of Coble creep equation. It is noted that another creep mechanism may act for each indentation load. The critical indentation depth for self-diffusion along the indenter/specimen is about $30 \mathrm{~nm}$ for ultrafine-grained $\mathrm{Cu}$ in the literature [36].The indentation depth in this experiment is $200 \mathrm{~nm}$, much longer than the critical indentation depth. As the indenter penetrates far away from the free surface of specimen and induces a much longer diffusion length, the self-diffusion along the indenter/specimen interface and along the free surface of the specimen will play fewer roles during the creep process [2] [37]. As grain size decrease 

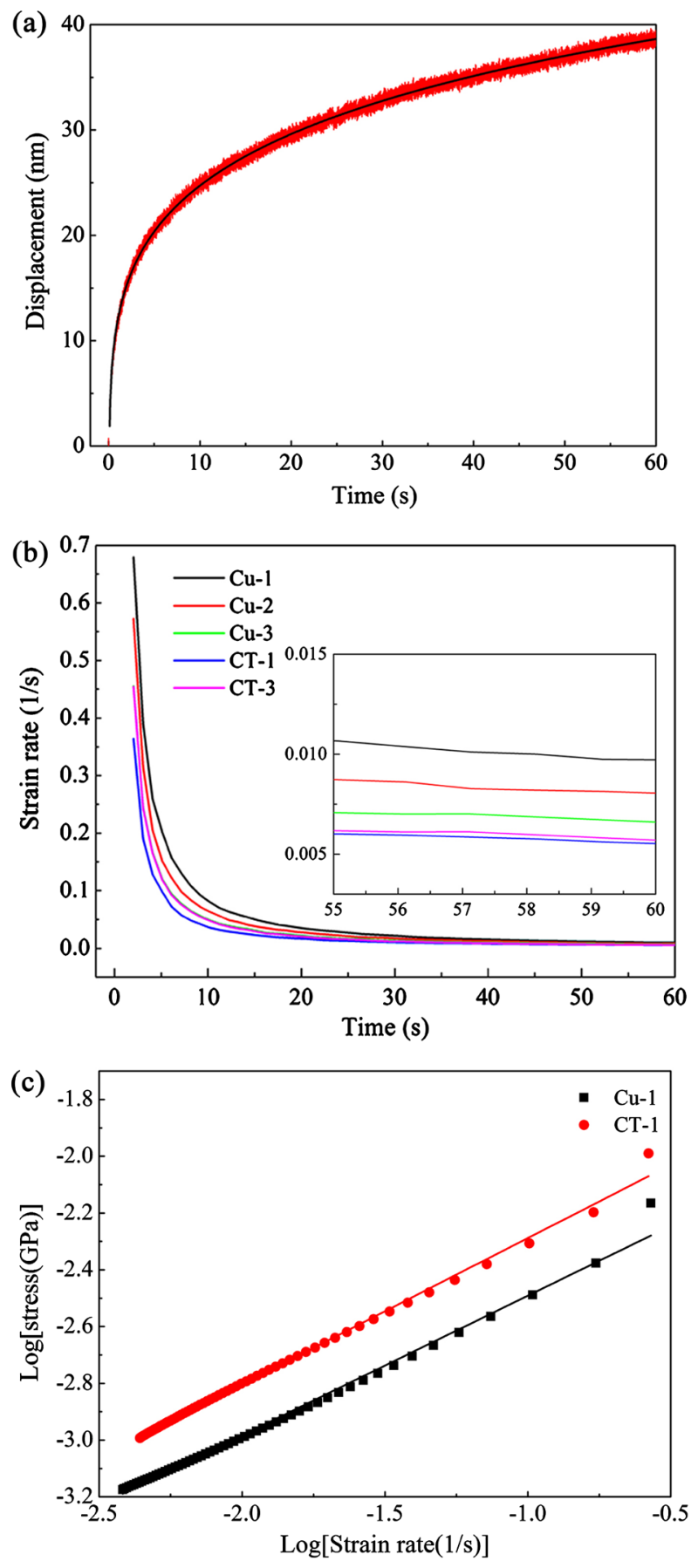

Figure 4. (a) Experimental and fitted creep curves of $\mathrm{NC} \mathrm{Cu}$ at $8 \mathrm{mN}$. The obtained fitting parameters of NC Cu are $\mathrm{h}_{0}=-9, \mathrm{a}=21, \mathrm{t}_{0}=2.5, \mathrm{~b}=0.2$, and $\mathrm{c}=-0.02$; (b) The calculated strain rate curves of NC Cu-1, 2, 3 and CT-1, 3 as a function of time; (c) The strain rate sensitivity $\mathrm{m}$ of $\mathrm{NC} \mathrm{Cu}-1$ and $\mathrm{CT}-1$ determined by the indentation creep test for each holding loads.

into the nanoscale, the GB activities including GB sliding and migration dominate the plastic deformation of NC materials. But in the $\mathrm{Cu}$-Ta alloy, the bigger Ta atoms are segregated in the GBs. It intensively suppresses the GB activities, which is proved by the very low creep strain rate of the $\mathrm{Cu}$-Ta alloy. Thus, the 
$\mathrm{Cu}$-Ta alloy shows a better thermal stability than NC copper.

\section{Conclusion}

In this paper, $\mathrm{NC} \mathrm{Cu}$-Ta alloy films were synthesized by magnetron sputtering on glass slides. As annealing at moderate temperature, the $\mathrm{NC} \mathrm{Cu}-\mathrm{Ta}$ alloy films show much better thermal stability than NC copper which is synthesized using the same method. The microstructure characterization implies that most tantalum atoms are segregated in the GBs. The creep tests suggest that the GB segregation of tantalum atom can effectively slow down the GB activities. That endows the $\mathrm{NC} \mathrm{Cu}$-Ta alloy with a good thermal stability. The experiment results inspire that GB segregation should be a good method to improve the stability of NC materials.

\section{Acknowledgements}

This work is supported by the National Key Research and Development Program of China (2018YFA0702304), the National Key Laboratory of Science and Technology on Helicopter Transmission (Nanjing University of Aeronautics and astronautics) (Grant No. HTL-O-19G10).

\section{Conflicts of Interest}

The authors declare no conflicts of interest regarding the publication of this paper.

\section{References}

[1] Gleiter, H. (1989) Nanocrystalline Materials. Progress in Materials Science, 33, 223-315. https://doi.org/10.1016/0079-6425(89)90001-7

[2] Chen, B., Lutker, K., Raju, S.V., Yan, J., Kanitpanyacharoen, W., Lei, J., et al. (2012) Texture of Nanocrystalline Nickel: Probing the Lower Size Limit of Dislocation Activity. Science, 338, 1448-1451. https://doi.org/10.1126/science.1228211

[3] Tang, C., Xiao, Z., Luo, F., Wang, J., Ma, C. and Zhang, W. (2012) Structural Characteristics and Magnetic Properties of Bulk Nanocrystalline Fe84Zr2Nb4B10 Alloy Prepared by Mechanical Alloying and Spark Plasma Sintering Consolidation. Rare Metals, 31, 255-259. https://doi.org/10.1007/s12598-012-0501-Z

[4] Wang, G., Lian, J., Jiang, Q., Sun, S. and Zhang, T.-Y. (2014) High Resolution Transmissionelectron Microscopic In-Situ Observations of Plastic Deformation of Compressed Nanocrystalline Gold. Journal of Applied Physics, 116, Article ID: 103518. https://doi.org/10.1063/1.4895550

[5] Shi, X.-B., Cui, L.-S., Liu, Z.-Y., Jiang, D.-Q. and Han, X.-D. (2014) Microstructure Ofstress-Induced Martensite in Nanocrystalline NiTi Shape Memory Alloy. RareMetals, 33, 379-82. https://doi.org/10.1007/s12598-014-0343-y

[6] Wang, G.Y., Lian, J.S. and Zhang, T.Y. (2013) High Resolution Transmission Electron Microscopy in Situ Investigation into the Spontaneous Coalescence of Gold Nanoparticles at Room Temperature. RSC Advances, 3, 24017-24020. https://doi.org/10.1039/c3ra43261k

[7] Fu, B., Han, J., Guo, S.-Q., Wang, Z., Zhang, P., Pan, Z.-J., et al. (2018) Room- 
Temperature and High-Temperature Magnetic Permeability of Co-Doped Nanocrystalline Alloys. Rare Metals, 37, 427-32. https://doi.org/10.1007/s12598-018-1037-7

[8] Li, H.-J., Wu, Q., Yue, M., Li, Y.-Q., Zhu, R.-C., Liang, J.-M., et al. (2020) Structure and Magnetic Properties of Nanocrystalline Dysprosium Powders. Rare Metals, 3, 28-35. https://doi.org/10.1007/s12598-018-01201-2

[9] Wang, G.Y., Jiang, Z.H., Jiang, Q. and Lian, J.S. (2008) Mechanical Behavior of an Electrodeposited Nanostructured $\mathrm{Cu}$ with a Mixture of Nanocrystalline Grains and Nanoscale Growth Twins in Submicrometer Grains. Journal of Applied Physics, 104, Article ID: 084305. https://doi.org/10.1063/1.2999379

[10] Bach, J., Stoiber, M., Schindler, L., Höppel, H.W. and Göken, M. (2020) Deformation Mechanisms and Strain Rate Sensitivity of Bimodal and Ultrafine-Grained Copper. Acta Materialia, 186, 363-373. https://doi.org/10.1016/j.actamat.2019.12.044

[11] Abdeljawad, F., Lu, P., Argibay, N., Clark, B.G., Boyce, B.L. and Foiles, S.M. (2017) Grainboundary Segregation in Immiscible Nanocrystalline Alloys. Acta Materialia, 126, 528-539. https://doi.org/10.1016/j.actamat.2016.12.036

[12] Sedeek, K., Makram, N., Hantour, H., Amer, T.Z. and Said, S.A. (2019) An Explicit and Novel Structure, Lattice Dynamics, and Photoemission of La-Doped Nanocrystalline SrZrO3 Perovskite. Rare Metals, 40, 105-112.

https://doi.org/10.1007/s12598-019-01326-y

[13] George, Z.V. and Mohammadreza, Y. (2016) Role of Grain Boundary on the Sources of Size Effects. Computational Materials Science, 117, 315-329.

https://doi.org/10.1016/j.commatsci.2016.01.025

[14] Prasad, M. and Chokshi, A.H. (2012) Deformation-Induced Thermally Activated Grain Growth in Nanocrystalline Nickel. Scripta Materialia, 67, 133-136. https://doi.org/10.1016/j.scriptamat.2012.03.041

[15] Gianola, D.S., Van Petegem, S., Legros, M., Brandstetter, S., Van Swygenhoven, H. and Hemker, K.J. (2006) Stress-Assisted Discontinuous Grain Growth and Its Effect on the Deformation Behavior of Nanocrystalline Aluminum Thin Films. Acta Materialia, 54, 2253-2263. https://doi.org/10.1016/j.actamat.2006.01.023

[16] Wang, J., Han, L., Li, X., Huang, Y., Liu, Y. and Wang, Z. (2020) Temperature-Dependent Evolution of Strength of Nanocrystalline Ni(Mo) Alloys at the Mo Solubility Limit. Materials Science and Engineering: A, 786, Article ID: 139326. https://doi.org/10.1016/j.msea.2020.139326

[17] Li, J.C.M. (2006) Mechanical Grain Growth in Nanocrystalline Copper. Physical Review Letters, 96, Article ID: 215506. https://doi.org/10.1103/PhysRevLett.96.215506

[18] Lin, Y., Zhu, J., Han, J., Ma, X. and Wang, G. (2020) Effect of Strains in Grain Boundary Modification on Plasticity and Plasticizing Mechanism of Commercial-Purity Nickel. Materials Today Communications, 24, Article ID: 101177. https://doi.org/10.1016/j.mtcomm.2020.101177

[19] Liu, C., Lu, W., Weng, G.J. and Li, J. (2019) A Cooperative Nano-Grain Rotation and Grain-Boundary Migration Mechanism for Enhanced Dislocation Emission and Tensile Ductility in Nanocrystalline Materials. Materials Science and Engineering: $A$, 756, 284-290. https://doi.org/10.1016/j.msea.2019.04.055

[20] Venkataraman, A., Linne, M., Daly, S. and Sangid, M.D. (2019) Criteria for the Prevalence of Grain Boundary Sliding as a Deformation Mechanism. Materialia, 8, Article ID: 100499. https://doi.org/10.1016/j.mtla.2019.100499

[21] Raviathul Basariya, M., Mukhopadhyay, N.K., Sripathi, S. and Padmanabhan, K.A. (2016) Grain Size Softening Effect in Intermetallics. Journal of Alloys and Com- 
pounds, 673, 199-204. https://doi.org/10.1016/j.jallcom.2016.02.258

[22] Cao, L. and Koslowsiki, M. (2015) Rate-Limited Plastic Deformation in Nanocrystalline Ni. Journal of Applied Physics, 117, Article ID: 244301.

https://doi.org/10.1063/1.4922812

[23] Cao, Y., Wang, Y.B., An, X.H., Liao, X.Z., Kawasaki, M., Ringer, S.P., Langdonc, T.G. and Zhu, Y.T. (2015) Grain Boundary Formation by Remnant Dislocations from the De-Twinning of Thin Nano-Twins. Scripta Materialia, 100, 98-101. https://doi.org/10.1016/j.scriptamat.2015.01.001

[24] Yu, H.L., Lu, C., Tieu, A.K., Li, H.J., Godbole, A., Kong, C. and Zhao, X. (2016) Simultaneous Grain Growth and Grain Refinement in Bulk Ultrafine-Grained Copper under Tensile Deformation at Room Temperature. Metallurgical and Materials Transactions $A$, 47, 3785-3789. https://doi.org/10.1007/s11661-016-3573-9

[25] Zhang, L., Lu, C., Zhang, J. and Tieu, K. (2016) A Dual Deformation Mechanism of Grain Boundary at Different Stress Stages. Materials Letters, 167, 278-283. https://doi.org/10.1016/j.matlet.2015.12.063

[26] Millett, P.C., Selvam, R.P. and Saxena, A. (2007) Stabilizing Nanocrystalline Materials with Dopants. Acta Materialia, 55, 2329-2336.

https://doi.org/10.1016/j.actamat.2006.11.028

[27] Renk O., Hohenwarter, A., Eder, K., Kormout, K.S., Cairney, J.M. and Pippan, R. (2015) Increasing the Strength of Nanocrystalline Steels by Annealing: Is Segregation Necessary? Scripta Materialia, 95, 27-30.

https://doi.org/10.1016/j.scriptamat.2014.09.023

[28] Darling, K.A., Robert, A.J., Mishin, Y., Mathaudhu, S.N. and Kecskes, L.J. (2013) Grain Size Stabilization of Nanocrystalline Copper at High Temperatures by Alloying with Tantalum. Journal of Alloys and Compounds, 573, 142-150. https://doi.org/10.1016/j.jallcom.2013.03.177

[29] Zeng, X., Fan, X.G., Li, H.W., Zhan, M. and Li, S.H. (2019) Grain Morphology Related Microstructural Developments in Bulk Deformation of 2219 Aluminum Alloy Sheet at Elevated Temperature. Materials Science and Engineering. A, 76, 328-338. https://doi.org/10.1016/j.msea.2019.06.022

[30] Darling, K.A., Rajagopalan, M., Komarasamy, M., Bhatia, M.A., Hornbuckle, B.C., Mishra, R.S. and Solanki, K.N. (2016) Extreme Creep Resistance in a Microstructurally Stable Nanocrystalline Alloy. Nature, 537, 378-381.

https://doi.org/10.1038/nature19313

[31] Li, H. and Ngan, A.H.W. (2003) Size Effects of Nanoindentation Creep. Journal of Materials Research, 19, 513-522. https://doi.org/10.1557/jmr.2004.19.2.513

[32] Gu, Y., Xiang, Y. and Srolovitz, D.J. (2016) Relaxation of Low-Angle Grain Boundary Structure by Climb of the Constituent Dislocations. Scripta Materialia, 114, 35-40. https://doi.org/10.1016/j.scriptamat.2015.11.016

[33] Kong, Q.P. and Fang, Q.F. (2016) Progress in the Investigations of Grain Boundary Relaxation. Critical Reviews in Solid State and Materials Sciences, 41, 192-216. https://doi.org/10.1080/10408436.2015.1135416

[34] Cao, Z.H., Lu, H.M., Meng, X.K. and Ngan, A.H.W. (2009) Indentation Size Dependent Plastic Deformation of Nanocrystalline and Ultrafine Grain Cu Films at Nanoscale. Journal of Applied Physics, 105, Article ID: 083521.

https://doi.org/10.1063/1.3110087

[35] Cao, Z.H., Lu, P.Y., Lu, H.M., Huang, Y.L., Zhou, Y.C. and Meng, X.K. (2009) Indentation Size Effects on the Creep Behavior of Nanocrystalline Tetragonal Ta films. Scripta Materialia, 60, 415-418. https://doi.org/10.1016/j.scriptamat.2008.11.016 
[36] Wang, F., Huang, P. and Xu, K.W. (2007) Time Dependent Plasticity at Real Nanoscale Deformation. Applied Physics Letters, 90, 161921.

https://doi.org/10.1063/1.2730735

[37] Li, W.B. and Warren, R. (1993) A Model for Nano-Indentation Creep. Acta Metallurgica et Materialia, 41, 3065-3069. https://doi.org/10.1016/0956-7151(93)90119-D 